\title{
Zinc-Oxide Thin-Film Transistor With Self-Aligned Source/Drain Regions Doped With Implanted Boron for Enhanced Thermal Stability
}

\author{
Zhi Ye, Lei Lu, and Man Wong, Senior Member, IEEE
}

\begin{abstract}
Because of the rapid diffusion of hydrogen in zinc oxide even at a relatively low temperature, zinc-oxide-based thinfilm transistors (TFTs) with hydrogen-doped source/drain regions suffer from degraded thermal stability. The use of boron, which is a heavier and a more slowly diffusing dopant, is systematically investigated as a replacement of hydrogen. Its effectiveness as a dopant has been studied in terms of a range of process conditions, including its implantation dosage and the subsequent heat treatment temperature, time, and ambience. The lowest resistivity of $2 \mathrm{~m} \Omega-\mathrm{cm}$ has been obtained at a boron dose of $10^{16} / \mathrm{cm}^{2}$. Self-aligned top-gated zinc-oxide TFTs with source/drain regions doped with implanted boron are shown to be more stable than those doped with hydrogen, even when subjected to the relatively high temperature needed for the formation of a good-quality passivation layer.
\end{abstract}

Index Terms-Boron, implantation, thin-film transistor (TFT), transparent electronics, zinc oxide ( $\mathrm{ZnO})$.

\section{INTRODUCTION}

$\mathbf{T}$ HE ADVANTAGES of metal-oxide-based thin-film transistors (TFTs) over their silicon-based counterparts are many: including transparency [1], high ON/OFF current ratio [2], reasonably high carrier mobility [3]-[5], relatively low processing temperature [6], etc. It is a small wonder that they are being hotly pursued for display and other applications [1], [7]-[9]. Among the many material candidates, zinc oxide $(\mathrm{ZnO})$ and its variants, such as indium-gallium zinc oxide (IGZO) [10], [11], have received the most attention.

Since hydrogen $(\mathrm{H})$ in $\mathrm{ZnO}$ is a shallow interstitial dopant [12] that can readily be activated at relatively low temperature, technologies for realizing self-aligned TFTs with H-doped source/drain (S/D) regions have already been reported [13][16]. Silicon nitride formed using plasma-enhanced chemical vapor deposition (PECVD) is commonly employed as a passivation layer. Its ability to protect a TFT against ambience, such as moisture [17]-[19], induced degradation could be enhanced if the PECVD was performed at an elevated temperature, say, $200{ }^{\circ} \mathrm{C}-300^{\circ} \mathrm{C}$. However, $\mathrm{H}$ is found to rapidly diffuse in $\mathrm{ZnO}$,

Manuscript received May 27, 2011; revised October 12, 2011; accepted November 2, 2011. Date of publication December 27, 2011; date of current version January 25, 2012. This work was supported by Grant 620907 from the Research Grants Council of the Hong Kong Special Administrative Region. The review of this paper was arranged by Editor H.-S. Tae.

The authors are with the Department of Electronic and Computer Engineering, The Hong Kong University of Science and Technology, Clear Water Bay, Kowloon, Hong Kong (e-mail. eemwong@ece.ust.hk).

Digital Object Identifier 10.1109/TED.2011.2175398 with an estimated diffusion coefficient of $\sim 8.7 \times 10^{-10} \mathrm{~cm}^{2} / \mathrm{s}$ at $300{ }^{\circ} \mathrm{C}$ [20]. The diffusion at such temperature of an excessive amount of $\mathrm{H}$ from the S/D into the channel region of a TFT may lead to an unacceptably high OFF-state leakage current [16], particularly for shorter-channel TFTs. Consequently, there is a tradeoff between limiting $\mathrm{H}$ diffusion and enhancing device stability.

To relax the restriction on the postprocessing temperature imposed by the rapid diffusion of $\mathrm{H}$, it is necessary to replace $\mathrm{H}$ with a slower diffusing dopant. More massive Group III elements, such as indium [21], [22], gallium [23], aluminum (Al) [24], and boron (B), are known n-type dopants in $\mathrm{ZnO}$ [25]. They have been incorporated in $\mathrm{ZnO}$ mostly to form transparent-conducting electrodes for solar cells [26] or lightemitting diodes [26], [27]. However, there have relatively been fewer reports on their application to the formation of the S/D regions in a self-aligned TFT. These include one [28] reporting on a ZnO TFT with the S/D regions doped using a diborane ion shower and an IGZO TFT with the S/D regions formed using an $\mathrm{Al}$ reaction method [29].

B, a dopant more commonly available than the other Group III elements, is presently investigated in greater detail as a dopant in $\mathrm{ZnO}$. Several techniques have already been employed to introduce $\mathrm{B}$ into $\mathrm{ZnO}$, such as ion implantation [30], metal-organic chemical vapor deposition [31], [32], atomic layer deposition [33], photo-atomic layer deposition [34], PECVD [35], and radio-frequency (RF) magnetron sputtering [36]. Among these, implantation is a more versatile technique in terms of process simplicity, dosage control, and compatibility with a variety of device structures. Hitherto, there has been little detailed report on the behavior of implanted B as a dopant in $\mathrm{ZnO}$. It is presently studied in terms of a range of process conditions, including dosage and the subsequent heat treatment temperature, time, and ambience. Self-aligned topgated $\mathrm{ZnO}$ TFTs with boron-doped S/D regions have been fabricated and characterized. They are verified to be more stable than those with H-doped S/D regions, even when subjected to the relatively high temperature needed for the formation of a good-quality passivation layer.

\section{EXPERIMENTAL}

The preparation of the samples for studying the behavior of implanted $\mathrm{B}$ as a dopant in $\mathrm{ZnO}$ started with the roomtemperature deposition of $100-\mathrm{nm}$-thick $\mathrm{ZnO}$ thin films on Corning Inc. Eagle-2000 glass substrates in a 13.56-MHz RF 
magnetron sputtering machine and an ambience of $10 \%$ oxygen $\left(\mathrm{O}_{2}\right)$ and $90 \%$ argon. A 50-nm-thick PECVD silicon dioxide $\left(\mathrm{SiO}_{2}\right)$ passivation layer was deposited at $300{ }^{\circ} \mathrm{C}$ on the resulting highly resistive films. $\mathrm{B}$ ions $\left(\mathrm{B}^{+}\right)$at $25 \mathrm{keV}$ with a dosage ranging over two orders of magnitude from $10^{14}$ to $1.2 \times 10^{16} / \mathrm{cm}^{2}$ were implanted into the $\mathrm{ZnO}$ thin films. The simulated projected range (SRIM2006) was $30 \mathrm{~nm}$ beyond the $\mathrm{SiO}_{2} / \mathrm{ZnO}$ interface. The implanted $\mathrm{B}$ was subsequently activated using different heat treatment schedules. The 50-nm-thick $\mathrm{SiO}_{2}$ passivation layer was removed with a sulfur hexafluoride $\left(\mathrm{SF}_{6}\right) / \mathrm{O}_{2}$ plasma after the first $5 \mathrm{~min}$ of heat treatment, thus making it possible to measure the sheet resistance using a four-point probe. The $\mathrm{ZnO}$ was exposed to a pure nitrogen $\left(\mathrm{N}_{2}\right)$ ambience during the subsequent heat treatments. An optical transmittance of $>91 \%$ was measured at a wavelength of $550 \mathrm{~nm}$ after the implanted thin films were heat treated at $500{ }^{\circ} \mathrm{C}$ for $20 \mathrm{~min}$ in $\mathrm{N}_{2}$.

The construction of the TFTs began with the sputter deposition of 100-nm-thick $\mathrm{ZnO}$ active layer on thermally oxidized silicon wafers. After the patterning of the active islands in a $0.1 \%$ aqueous hydrofluoric acid solution, a layer of 100-nmthick PECVD $\mathrm{SiO}_{2}$ was deposited at $300{ }^{\circ} \mathrm{C}$ as the gate dielectric. This oxide layer also protected the $\mathrm{ZnO}$ from being exposed to ambient $\mathrm{O}_{2}$ and moisture during the subsequent processes. A 130-nm-thick indium-tin oxide gate electrode was sputter deposited at room temperature and patterned using a liftoff process. For comparison, both $\mathrm{H}$ and $\mathrm{B}$ were investigated as dopants to form the self-aligned S/D regions.

For the TFTs with $\mathrm{H}$-doped S/D regions, the doping process started with a 5-min heat treatment at $450{ }^{\circ} \mathrm{C}$ in an $\mathrm{O}_{2}$ ambience. The gate dielectric above the $\mathrm{S} / \mathrm{D}$ regions was subsequently etched in an $\mathrm{SF}_{6} / \mathrm{O}_{2}$ plasma before the exposed $\mathrm{S} / \mathrm{D}$ regions were doped n-type during a 5-min immersion in an $\mathrm{H}_{2}$ plasma in an Oxford Plasmalab 80 Plus reactive ion etcher. For the TFTs with B-doped S/D regions, the doping was accomplished by the implantation of $35 \mathrm{keV} \mathrm{B}^{+}$at a dose of $5 \times 10^{15} / \mathrm{cm}^{2}$. A heat treatment at $450{ }^{\circ} \mathrm{C}$ for $10 \mathrm{~min}$ in $\mathrm{N}_{2}$ was performed to activate the implanted $\mathrm{B}$, resulting in a resistivity of $\sim 10 \mathrm{~m} \Omega-\mathrm{cm}$ in the $\mathrm{S} / \mathrm{D}$ regions.

The respective deposition temperatures of a 400-nm-thick PECVD silicon nitride passivation layer on the TFTs with $\mathrm{H}$ - and B-doped S/D regions are $80{ }^{\circ} \mathrm{C}$ and $300{ }^{\circ} \mathrm{C}$. Contact holes were opened before $\mathrm{Al}$ was deposited and patterned to form the metal leads. A schematic illustration and a photo of the fabricated TFT are shown in Fig. 1. The electrical properties of the TFTs were characterized using an HP 4145B Semiconductor Parameter Analyzer.

\section{RESULTS AND DISCUSSION}

Consistent with the published reports [31], [35] that B is a substitutional donor at the $\mathrm{Zn}$ lattice site, it was verified using Hall effect measurement that the B-doped $\mathrm{ZnO}$ films were n-type. The dependence of the resistivity, computed as the product of the measured sheet resistance and the thickness of the $\mathrm{ZnO}$, on the heat treatment schedules of $\mathrm{ZnO}$ with a B implant dose of $10^{16} / \mathrm{cm}^{2}$ is shown in Fig. 2. At the end of the first $5 \mathrm{~min}$ of heat treatment, the resistivity decreases
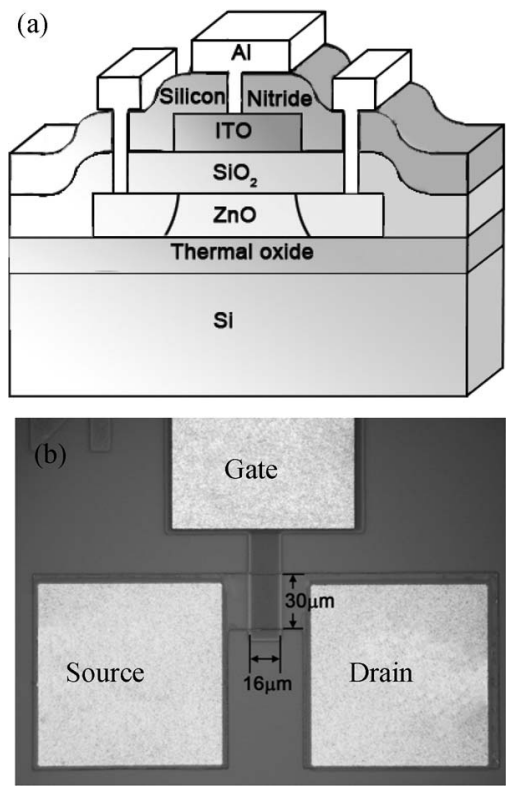

Fig. 1. (a) Schematic illustration of the TFT structure and (b) optical micrograph of a fabricated TFT with respective channel width and length of $30 \mu \mathrm{m}$ and $16 \mu \mathrm{m}$.

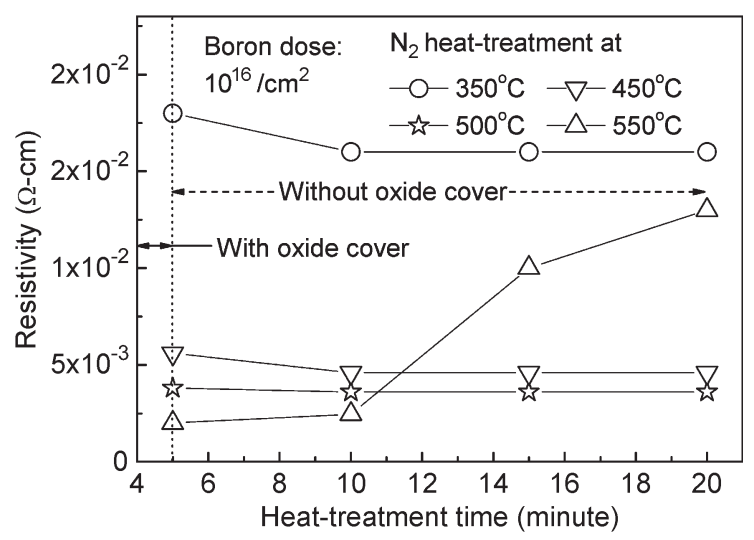

Fig. 2. Dependence of resistivity on the heat treatment time for $\mathrm{ZnO}$ thin films doped with $\mathrm{B}$ at a dose of $10^{16} / \mathrm{cm}^{2}$.

with increasing temperature. A lowest value of $2 \mathrm{~m} \Omega$-cm was obtained for the sample heat treated at $550{ }^{\circ} \mathrm{C}$. At heat treatment temperatures below $550{ }^{\circ} \mathrm{C}$, the resistivity decreased with increasing time and saturated beyond $10 \mathrm{~min}$. An opposite trend is observed for the sample heat treated at $550{ }^{\circ} \mathrm{C}$. This was probably caused by the diffusion of B toward either the top exposed surface or the bottom glass interface of the $\mathrm{ZnO}$. The subsequent evaporation of $\mathrm{B}$ from the former or the diffusion of $\mathrm{B}$ across the latter into the glass substrate clearly overwhelmed the higher degree of activation of the implanted B during a more extended heat treatment, thus leading to an overall reduction in the B concentration and an increase in the resistivity of the $\mathrm{ZnO}$ film.

The resistivity, the Hall effect carrier concentration, and the Hall effect mobility were measured for B-implanted $\mathrm{ZnO}$ activated at $450{ }^{\circ} \mathrm{C}$ for $10 \mathrm{~min}$ in an $\mathrm{N}_{2}$ ambience. Their dependence on the dose of $\mathrm{B}$, ranging from $10^{15}$ to $1.2 \times 10^{16} / \mathrm{cm}^{2}$, is shown in Fig. 3. For a 100-nm-thick $\mathrm{ZnO}$ film, this dose range corresponds to an apparent volume doping concentration 


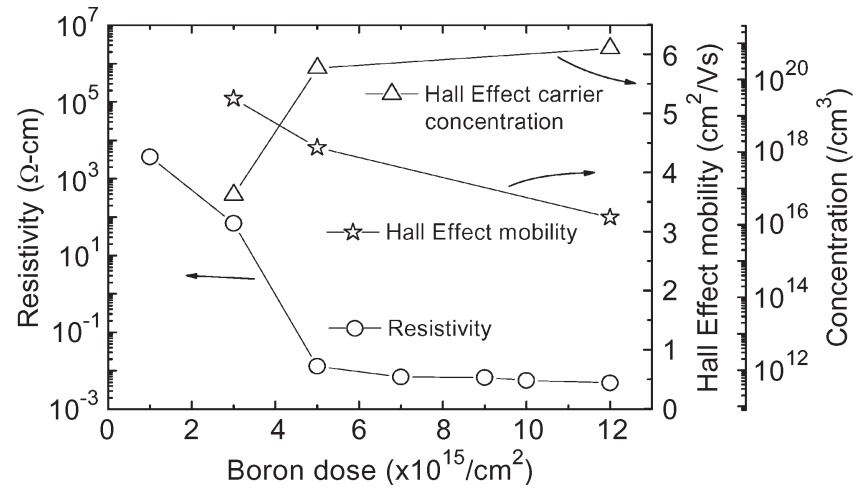

Fig. 3. Dependence of resistivity, Hall effect carrier concentration, and Hall effect mobility on the $\mathrm{B}$ dose. The heat treatment condition for dopant activation was $450{ }^{\circ} \mathrm{C}$ for $10 \mathrm{~min}$ in an $\mathrm{N}_{2}$ ambience.

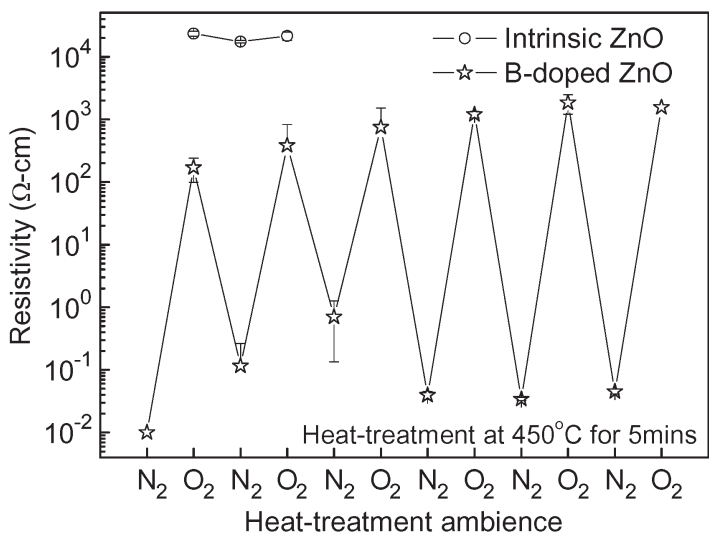

Fig. 4. Dependence of resistivity on the heat treatment ambience $\left(\mathrm{N}_{2}\right.$ or $\left.\mathrm{O}_{2}\right)$ for intrinsic $\mathrm{ZnO}$ or $\mathrm{ZnO}$ doped with $\mathrm{B}$ at a dose of $10^{16} / \mathrm{cm}^{2}$.

ranging from $10^{20}$ to $1.2 \times 10^{21} / \mathrm{cm}^{3}$. The resistivity is seen to monotonically decrease with increasing $\mathrm{B}$ dose, with a steeper transition observed between the dose of $2 \times 10^{15}$ and $5 \times 10^{15} / \mathrm{cm}^{2}$. Concurrent with the steeper drop in resistivity is a steeper rise in the Hall effect carrier concentration that is always smaller than the apparent doping concentration. Such behavior is typical for the doping of polycrystalline semiconducting thin films, with the filling of grain boundary or other traps responsible for the steeper transition regions [37] in both the resistivity and the carrier concentration. The measured Hall effect mobility is in the range of $3 \sim 5 \mathrm{~cm}^{2} / \mathrm{Vs}$.

The influence of the heat treatment ambience on the resistivity of $\mathrm{ZnO}$ implanted with $10^{16} / \mathrm{cm}^{2} \mathrm{~B}$ was studied by subjecting the samples to cyclical 5-min heating at $450{ }^{\circ} \mathrm{C}$ in an oxidizing $\mathrm{O}_{2}$ or an inert $\mathrm{N}_{2}$ ambient. The corresponding resistivity after each treatment cycle was measured, and its evolution is shown in Fig. 4. It is apparent that the cyclical change in heat treatment ambience induced a corresponding change in resistivity, with the value obtained after heat treatment in an $\mathrm{O}_{2}$ ambience $\sim 10^{5}$ times higher than that obtained after heat treatment in an $\mathrm{N}_{2}$ ambience. The cyclical change in resistivity would be consistent with a reversible mechanism behind the change in resistivity.

The dependence of the resistivity on the heat treatment ambience seems to correlate well with the popular proposition that an oxygen vacancy is a donor in $\mathrm{ZnO}$ [38]: with the population of the vacancies respectively decreased or increased after heat treatment in an $\mathrm{O}_{2}$ or an $\mathrm{N}_{2}$ ambience. X-ray photoelectron spectroscopy (XPS) was employed to study the effects of heat treatment on the chemical state of oxygen in intrinsic and B-doped $\mathrm{ZnO}$. The corresponding spectra are shown in Fig. 5. For both $\mathrm{O}_{2}$ and $\mathrm{N}_{2}$ heat treatment ambience, the binding energy of $\mathrm{Zn}-2 \mathrm{p}_{3 / 2}$ was unchanged at $1022.0 \mathrm{eV}$ and similar to that measured in bulk $\mathrm{ZnO}$ [39]. The O-1s peak can be fitted using three subpeaks [40] centered at $E_{1}=530.15, E_{2}=$ 531.25, and $E_{3}=532.40 \pm 0.15 \mathrm{eV}$, corresponding respectively to lattice oxygen in $\mathrm{ZnO}, \mathrm{O}^{2-}$ in an oxygen vacancy in $\mathrm{ZnO}$, and oxygen associated with species such as $-\mathrm{CO}_{3}$, water, or $\mathrm{O}_{2}$ loosely adsorbed on the surface of the $\mathrm{ZnO}$ sample. For both intrinsic and B-doped samples, the relative intensities of the $E_{2}$ peak (defined as the ratio of the intensity at $E_{2}$ to the sum of the intensities at $E_{1}, E_{2}$ and $E_{3}$ ) indeed increased after heat treatment in an $\mathrm{N}_{2}$ ambience, thus verifying a corresponding increase in the oxygen vacancy concentration.

The correlation between the resistivity and the vacancy concentration was then tested by monitoring the resistivity of intrinsic $\mathrm{ZnO}$ subjected to the same cyclical heat treatment. The results are also summarized in Figs. 4 and 5, showing a relatively high resistivity of $\sim 2 \times 10^{4} \Omega$-cm and only a rather weak dependence on the heat treatment ambience. Perhaps either the 5-min heat treatment time per cycle was too short to induce a sufficient change in the population of oxygen vacancies to influence the resistivity, or the consistently high resistivity of the intrinsic sample has more to do with the prediction of density functional calculation [41] that such a vacancy, at $\sim 1 \mathrm{eV}$ below the conduction band minimum, cannot be an effective donor at room temperature; it is clear that the dependence of the resistivity of B-implanted $\mathrm{ZnO}$ on heat treatment ambience cannot be attributed to a corresponding change in the population of oxygen vacancies.

It is presently suggested that B substituted for $\mathrm{Zn} \mathrm{[30]} \mathrm{can} \mathrm{be}$ oxidized in an $\mathrm{O}_{2}$ ambience. Such oxidized $\mathrm{B}$ is removed from $\mathrm{ZnO}$ as a donor. During the heat treatment in an $\mathrm{N}_{2}$ ambience, the reaction is reversed, and the reduced substitutional $B$ is reinstated as a donor [42]. The binding energy of B-1s measured using XPS increases with the oxidation state of B toward a value of $\sim 193 \mathrm{eV}$ obtained for boron oxide $\left(\mathrm{B}_{2} \mathrm{O}_{3}\right)$. Shown in Fig. 6 are the XPS spectra of B-1s obtained from the same B-doped samples heat-treated sequentially and cyclically in an $\mathrm{N}_{2}$ or an $\mathrm{O}_{2}$ ambience. The peak for the sample after heat treatment in $\mathrm{O}_{2}$ appears to be $\sim 0.25 \mathrm{eV}$ larger than that for the same sample after the initial heat treatment in $\mathrm{N}_{2}$ or in $\mathrm{N}_{2}$ again after having been heat treated in $\mathrm{O}_{2}$. Such reversibility correlates well with the cyclical change in the resistivity of B-doped $\mathrm{ZnO}$ (Fig. 4) after being alternately heat treated in an $\mathrm{N}_{2}$ or an $\mathrm{O}_{2}$ ambience. If the goal is to obtain the lowest resistivity in a $\mathrm{B}$-doped $\mathrm{ZnO}$ for a given dose, as in the S/D regions of a TFT, then heat treatment in an oxidizing ambient should be avoided.

The thermal stability of TFTs with self-aligned $\mathrm{H}$ - and B-doped S/D regions is next compared. Shown in Fig. 7 is a comparison of the evolution of the transfer characteristics (the drain current $I_{D}$ versus the gate-to-source bias $V_{\mathrm{GS}}$ at a drain-to-source bias $V_{\mathrm{DS}}$ of $5 \mathrm{~V}$ ) of these TFTs when subjected 


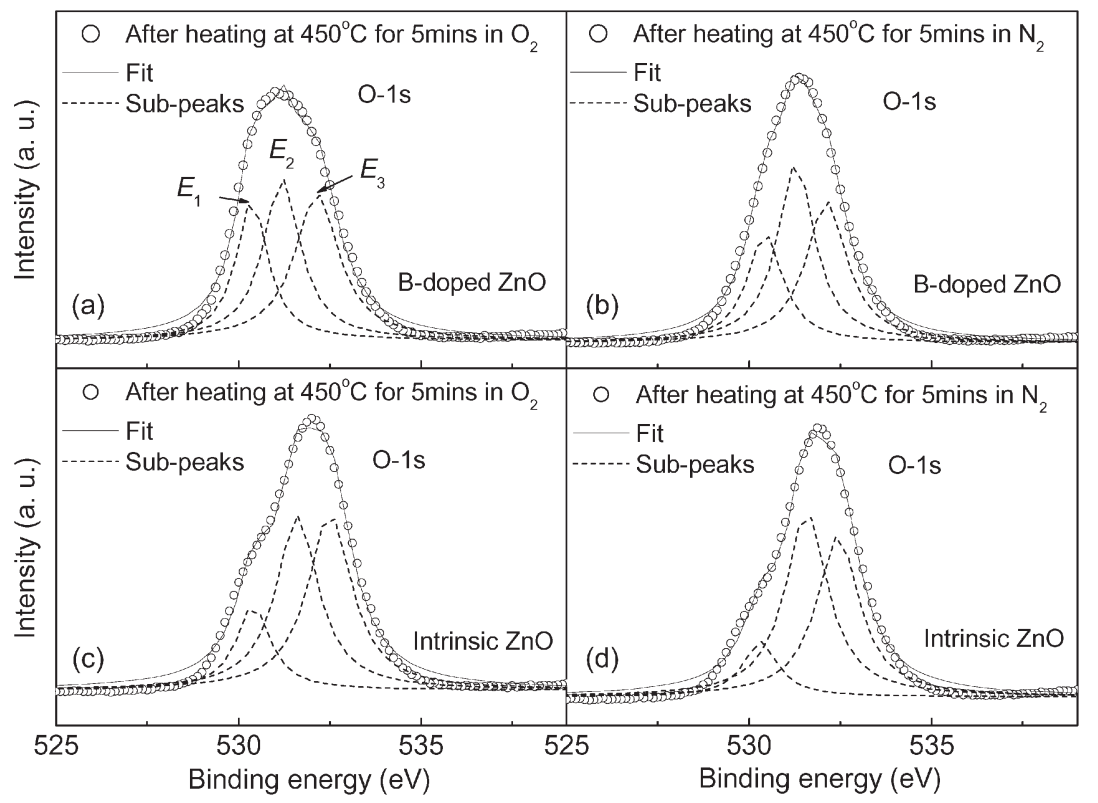

Fig. 5. XPS spectra of O-1s peaks for B-doped $\mathrm{ZnO}$ thin film heat treated in (a) $\mathrm{O}_{2}$ and (b) $\mathrm{N}_{2}$, and intrinsic $\mathrm{ZnO}$ thin film heat treated in (c) $\mathrm{O}_{2}$ and (d) $\mathrm{N}_{2}$.

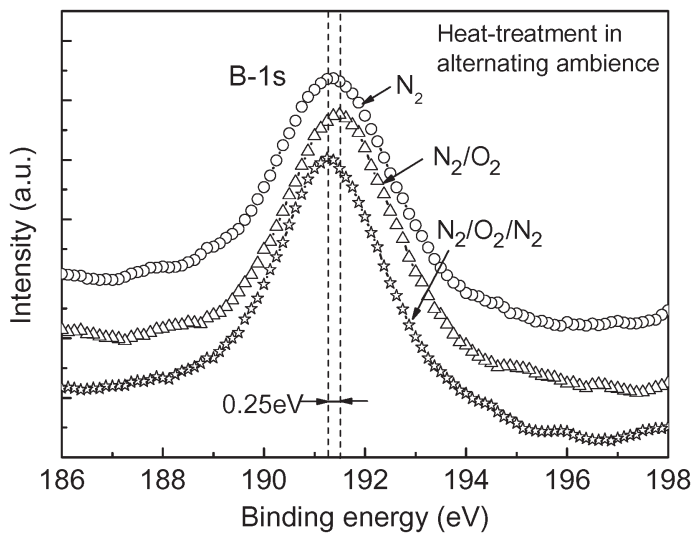

Fig. 6. XPS spectra of the B-1s peaks of B-doped $\mathrm{ZnO}$ thin films heat treated alternately in an $\mathrm{N}_{2}$ or $\mathrm{O}_{2}$ ambience.

to a series of heat treatments. As the TFT with H-doped S/D regions was sequentially heat treated at $110{ }^{\circ} \mathrm{C}$ for $20 \mathrm{~min}$ and $150{ }^{\circ} \mathrm{C}$ for $20 \mathrm{~min}$, progressive reductions in both $I_{D}$ and the pseudosubthreshold slope $(S S)$ were observed. This trend is attributed to the continuous diffusion of $\mathrm{H}$ out of the S/D regions and some of it into the channel region, as shown in the inset of Fig. 7(a). The device was "shorted" after an additional heat treatment at $150{ }^{\circ} \mathrm{C}$ for $25 \mathrm{~min}$.

The output ( $I_{D}$ versus $\left.V_{\mathrm{DS}}\right)$ and transfer (with $V_{\mathrm{DS}}=5 \mathrm{~V}$ ) characteristics of a TFT with B-doped S/D regions are shown in Fig. 7(b). The respective channel width $W$ and length $L$ are 30 and $16 \mu \mathrm{m}$. The linear dependence of $I_{D}$ on $V_{\mathrm{DS}}$ at low $V_{\mathrm{DS}}$ in the output characteristics [Inset of Fig. 7(b)] is an indication that the B-doped S/D regions form good ohmic contacts with Al. From the transfer characteristics [Fig. 7(b)], a linearly extrapolated threshold voltage $V_{\mathrm{th}}$ of $\sim 0.1 \mathrm{~V}$, an $S S$ of $\sim 0.2$ V/decade, an ON/OFF current ratio of $\sim 10^{6}$ and a field effect mobility $\mu_{\mathrm{FE}}$ of $\sim 2 \mathrm{~cm}^{2} / \mathrm{Vs}$ can be extracted from the dependence of $I_{D}$ on $V_{\mathrm{GS}}$ in the saturation regime [4]. The TFT was subsequently heat treated at $300{ }^{\circ} \mathrm{C}$ for $1 \mathrm{~h}$.
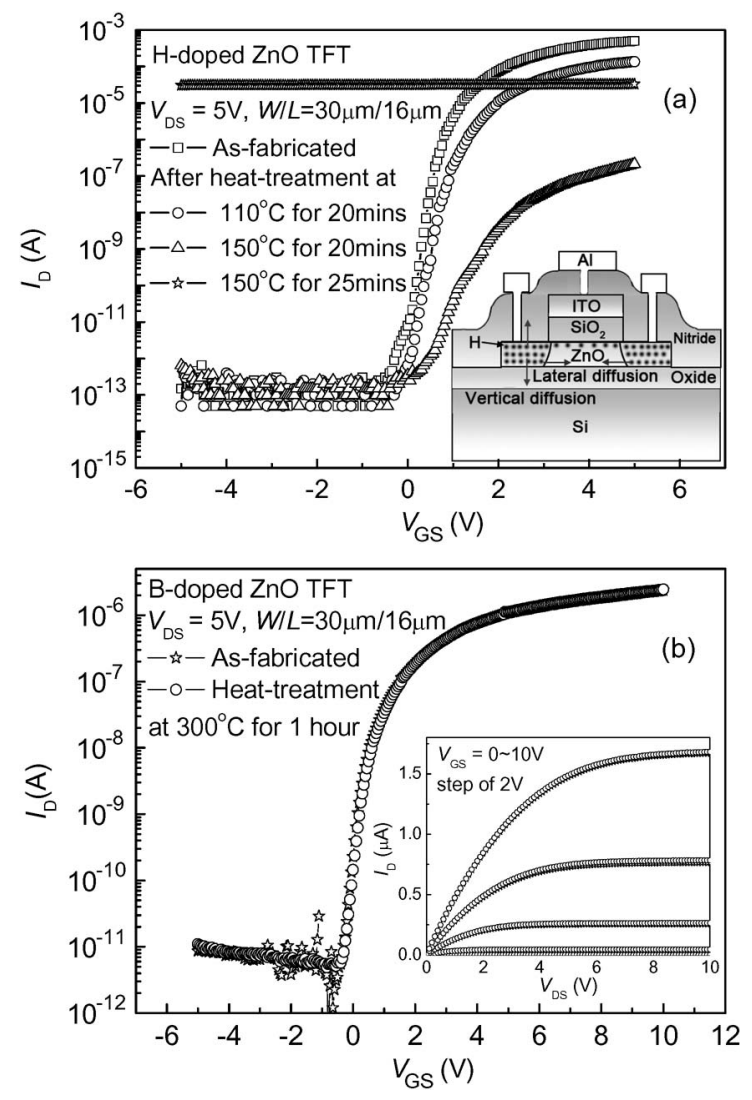

Fig. 7. (a) Effects of heat treatment on the transfer characteristics of H-doped $\mathrm{ZnO}$ TFT and (b) transfer and output (shown in the Inset) characteristics of B-doped ZnO TFT measured immediately after fabrication and after an additional heat treatment at $300{ }^{\circ} \mathrm{C}$ for $1 \mathrm{~h}$ in an $\mathrm{N}_{2}$ ambience.

The resulting transfer and output characteristics overlap those extracted before the heat treatment, thus demonstrating greatly improved thermal stability compared with that of a TFT with $\mathrm{H}$-doped S/D regions. The transfer characteristics of TFTs with B-doped S/D regions and $L=16,8,4$, and $2 \mu \mathrm{m}$ are shown in 

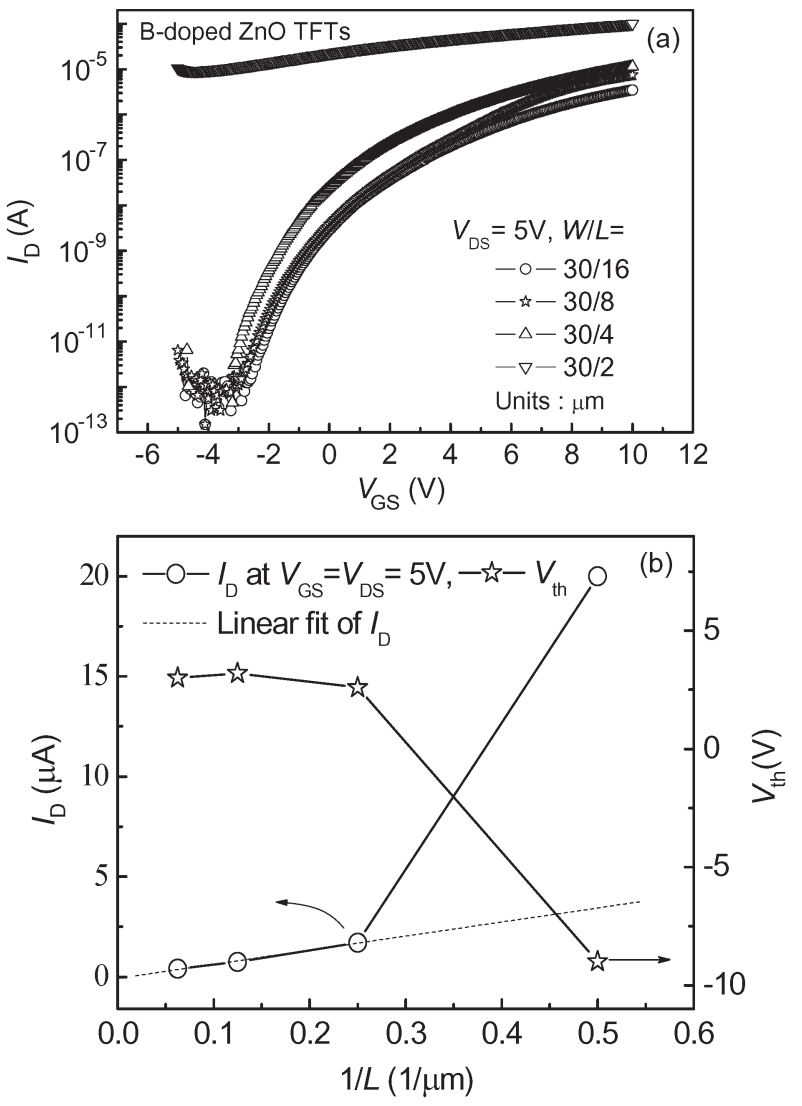

Fig. 8. (a) Transfer characteristics of B-doped $\mathrm{ZnO}$ TFTs with the same $W=30 \mu \mathrm{m}$ but different $L=16,8,4$, and $2 \mu \mathrm{m}$. (b) Dependences of $\left.I_{D}\right|_{V_{\mathrm{GS}}=V_{\mathrm{DS}}=5 \mathrm{~V}}$ and $V_{\mathrm{th}}$ on $1 / L$ for ZnO TFTs with $W=30 \mu \mathrm{m}$. The dashed line represents the trend of linear scaling with $1 / L$.

Fig. 8(a). Except for the $S S$ of the TFT with $L=2 \mu \mathrm{m}$ that exhibits a relative loss of gate control due to the finite lateral diffusion of B into the channel region, those of the other TFTs scale nicely with $L$. The TFTs were biased in saturation by setting $V_{\mathrm{GS}}=V_{\mathrm{DS}}$. The dependences of $\left.I_{D}\right|_{V_{\mathrm{GS}}=V_{\mathrm{DS}}=5 \mathrm{~V}}$ and $V_{\text {th }}$ versus $1 / L$ are shown in Fig. 8(b). It can be seen that $I_{D}$ scales linearly with $L$, and $V_{\mathrm{th}}$ is relatively independent of $1 / L$ for $L>2 \mu \mathrm{m}$. Clearly, the TFTs with B-doped S/D regions can be scaled to $L \sim 2 \mu \mathrm{m}$ without manifesting significant shortchannel effects.

The improvement in device stability against moisture exposure resulting from a passivation layer deposited at a higher temperature is demonstrated in the comparison shown in Fig. 9. The TFTs were stressed in an environmental chamber at a $98 \%$ relative humidity at room temperature in air. It is clearly seen that the transfer characteristics of the TFT with H-doped S/D regions, with a passivation layer deposited at $80{ }^{\circ} \mathrm{C}$, degraded significantly after 3 days of exposure to moisture, whereas those of the TFT with B-doped S/D regions, with a passivation layer deposited at $300{ }^{\circ} \mathrm{C}$, were unchanged even after 7 days of exposure.

\section{CONCLUSion}

The use of boron, which is a heavier and more slowly diffusing donor, has been systematically investigated as a re-
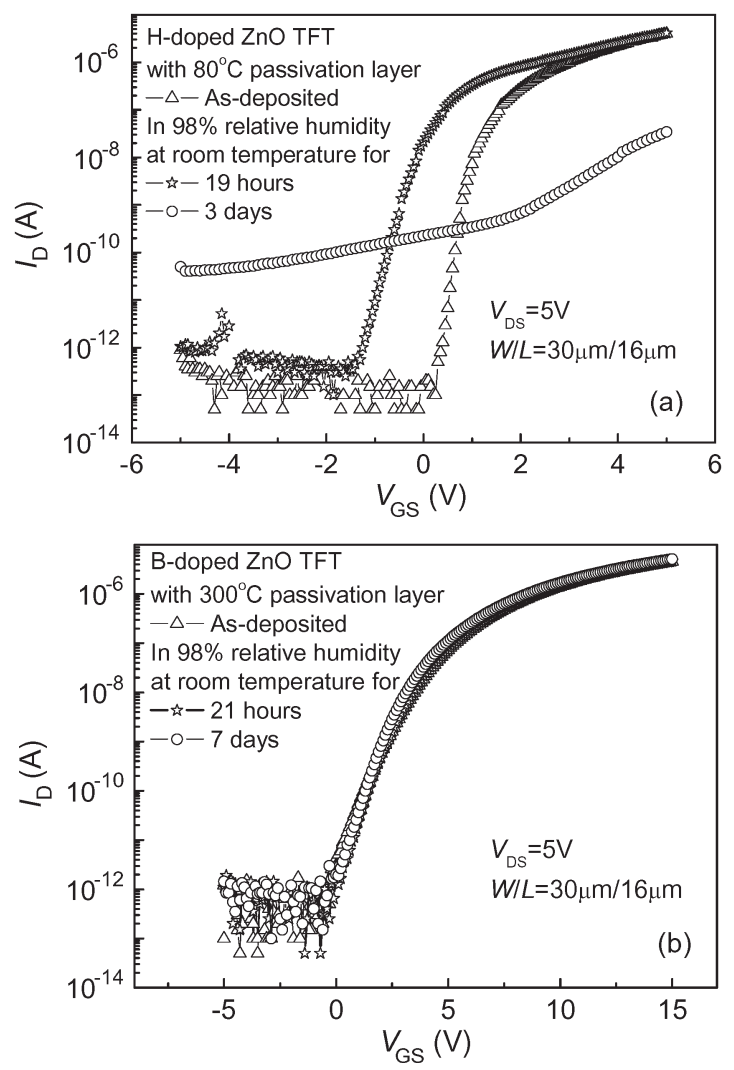

Fig. 9. Evolution of the transfer characteristics of $\mathrm{H}$ - and B-doped $\mathrm{ZnO}$ TFTs passivated respectively with PECVD silicon nitride deposited at (a) $80{ }^{\circ} \mathrm{C}$ and (b) $300{ }^{\circ} \mathrm{C}$, after being exposed to a $98 \%$ relative humidity environment at room temperature in air for different durations.

placement of hydrogen for forming the source/drain regions of a zinc oxide TFT. Resistivity as low as $2 \mathrm{~m} \Omega$-cm can be achieved for a boron dose of $10^{16} / \mathrm{cm}^{2}$ if subjected to an activation schedule of $550{ }^{\circ} \mathrm{C}$ for $5 \mathrm{~min}$ in a nitrogen ambience. Heat treatment in an oxidizing ambience should be avoided after the introduction of boron, since the oxidation of substitutional boron greatly increases the resistivity of the film, thus also the parasitic source/drain resistance of the corresponding transistor. Significantly enhanced thermal stability is demonstrated for transistors with boron-doped source/drain regions, particularly when compared to those with hydrogen-doped source/drain regions. Consequently, a better quality passivation layer, deposited at a temperature as high as $300^{\circ} \mathrm{C}$, can be applied.

\section{REFERENCES}

[1] J. F. Wager, "Transparent electronics," Science, vol. 300, no. 5623, pp. 1245-1246, May 2003.

[2] H. H. Hsieh and C. C. Wu, "Amorphous $\mathrm{ZnO}$ transparent thin-film transistors fabricated by fully lithographic and etching processes," Appl. Phys. Lett., vol. 91, no. 1, pp. 013502-1-013502-3, Jul. 2007.

[3] R. L. Hoffman, B. J. Norris, and J. F. Wager, "ZnO-based transparent thinfilm transistors," Appl. Phys. Lett., vol. 82, no. 5, pp. 733-735, Feb. 2003.

[4] H. H. Hsieh and C. C. Wu, "Scaling behavior of $\mathrm{ZnO}$ transparent thinfilm transistors," Appl. Phys. Lett., vol. 89, no. 4, pp. 041109-1-041109-3, Jul. 2006.

[5] C. S. Li, Y. N. Li, Y. L. Wu, B. S. Ong, and R. O. Loutfy, "Fabrication conditions for solution-processed high-mobility $\mathrm{ZnO}$ thin-film transistors," J. Mater. Chem., vol. 19, pp. 1626-1634, Feb. 2009.

[6] E. M. C. Fortunato, P. M. C. Barquinha, A. Pimentel, A. M. F. Goncalves, A. J. S. Marques, R. F. P. Martins, and L. M. N. Pereira, "Wide-bandgap 
high-mobility $\mathrm{ZnO}$ thin-film transistors produced at room temperature," Appl. Phys. Lett., vol. 85, no. 13, pp. 2541-2543, Sep. 2004.

[7] P. F. Carcia, R. S. McLean, M. H. Reilly, and G. Nunes, "Transparent ZnO thin-film transistor fabricated by RF magnetron sputtering," Appl. Phys. Lett., vol. 82, no. 7, pp. 1117-1119, Feb. 2003.

[8] T. Hirao, M. Furuta, T. Hiramatsu, T. Matsuda, C. Y. Li, H. Furuta, H. Hokari, M. Yoshida, H. Ishii, and M. Kakegawa, "Bottom-gate zinc oxide thin-film transistors (ZnO TFTs) for AM-LCDs," IEEE Trans. Electron Devices, vol. 55, no. 11, pp. 3136-3142, Nov. 2008.

[9] I. Song, S. Kim, H. X. Yin, C. J. Kim, J. Park, S. Kim, H. S. Choi, E. Lee, and Y. Park, "Short channel characteristics of GalliumIndium-Zinc-Oxide thin film transistors for three-dimensional stacking memory," IEEE Electron Device Lett., vol. 29, no. 6, pp. 549-552, Jun. 2008.

[10] H. Hosono, K. Nomura, H. Ohta, A. Takagi, T. Kamiya, and M. Hirano, "Room-temperature fabrication of transparent flexible thin-film transistors using amorphous oxide semiconductors," Nature, vol. 432, no. 7016, pp. 488-492, Nov. 2004.

[11] T. Kamiya, K. Nomura, and H. Hosono, "Present status of amorphous In-Ga-Zn-O thin-film transistors," Sci. Technol. Adv. Mater, vol. 11, pp. 044305-1-044305-23, Aug. 2010.

[12] C. G. L. Van de Walle, "Hydrogen as a cause of doping in zinc oxide," Phys. Rev. Lett., vol. 85, no. 5, pp. 1012-1015, Jul. 2000.

[13] S. Kim, J. Park, C. J. Kim, H. Song, S. Kim, S. Park, H. Yin, H. I. Lee, E. Lee, and Y. Park, "Source/drain formation of self-aligned top-gate amorphous GaInZnO thin-film transistors by $\mathrm{NH}_{3}$ plasma treatment," IEEE Electron Device Lett., vol. 30, no. 4, pp. 374-376, Apr. 2009.

[14] A. Sato, K. Abe, R. Hayashi, H. Kumomi, K. Nomura, T. Kamiya, M. Hirano, and H. Hosono, "Amorphous In-Ga-Zn-O coplanar homojunction thin-film transistor," Appl. Phys. Lett., vol. 94, no. 13, pp. 133502-1-133502-3, Mar. 2009.

[15] B. Du Ahn, H. S. Shin, H. J. Kim, J. S. Park, and J. K. Jeong, "Comparison of the effects of $\mathrm{Ar}$ and $\mathrm{H}_{2}$ plasmas on the performance of homojunctioned amorphous indium gallium zinc oxide thin film transistors," Appl. Phys. Lett., vol. 93, no. 20, pp. 203506-1-203506-3, Nov. 2008.

[16] C. H. Wu, H. H. Hsieh, C. W. Chien, and C. C. Wu, "Self-aligned top-gate coplanar In-Ga-Zn-O thin-film transistors," J. Display Technol., vol. 5, no. 12 , pp. $515-519$, Dec. 2009

[17] J. S. Park, J. K. Jeong, H. J. Chung, Y. G. Mo, and H. D. Kim, "Electronic transport properties of amorphous indium-gallium-zinc oxide semiconductor upon exposure to water," Appl. Phys. Lett., vol. 92, no. 7, pp. 072104-1-072104-3, Feb. 2008.

[18] T. C. C. Wan, F. Chung, H. W. Li, C. W. Chen, Y. C. Chen, S. C. Chen, T. Y. Tseng, and Y. H. Tai, "Influence of $\mathrm{H}_{2} \mathrm{O}$ dipole on subthreshold swing of amorphous indium-gallium-zinc-oxide thin film transistors," Electrochem. Solid-State Lett., vol. 14, no. 3, pp. H114-H116, Dec. 2011.

[19] O. Nakagawara, Y. Kishimoto, H. Seto, Y. Koshido, Y. Yoshino, and T. Makino, "Moisture-resistant $\mathrm{ZnO}$ transparent conductive films with $\mathrm{Ga}$ heavy doping," Appl. Phys. Lett., vol. 89, no. 9, pp. 091904-1-091904-3, Aug. 2006.

[20] K. Ip, M. E. Overberg, Y. W. Heo, D. P. Norton, S. J. Pearton, C. E. Stutz, B. Luo, F. Ren, D. C. Look, and J. M. L. Zavada, "Hydrogen incorporation and diffusivity in plasma-exposed bulk $\mathrm{ZnO,"} \mathrm{Appl.} \mathrm{Phys.} \mathrm{Lett.,} \mathrm{vol.} \mathrm{82,}$ no. 3, pp. 385-387, Jan. 2003.

[21] S. Major, A. Banerjee, and K. L. Chopra, "Highly transparent and conducting indium-doped zinc-oxide films by spray pyrolysis," Thin Solid Films, vol. 108, no. 3, pp. 333-340, Oct. 1983.

[22] P. M. R. Kumar, C. S. Kartha, K. P. Vijayakumar, T. Abe, Y. Kashiwaba, F. Singh, and D. K. Avasthi, "On the properties of indium doped ZnO thin films," Semicond. Sci. Technol., vol. 20, no. 2, pp. 120-126, Feb. 2005

[23] M. S. Oh, D. K. Hwang, D. J. Seong, H. S. Hwang, S. J. Park, and E. Do Kim, "Improvement of characteristics of Ga-doped $\mathrm{ZnO}$ grown by pulsed laser deposition using plasma-enhanced oxygen radicals," J. Electrochem. Soc., vol. 155, no. 9, pp. D599-D603, Jul. 2008.

[24] K. K. Kim, S. Niki, J. Y. Oh, J. O. Song, T. Y. Seong, S. J. Park, S. Fujita, and S. W. Kim, "High electron concentration and mobility in Al-doped $\mathrm{n}-\mathrm{ZnO}$ epilayer achieved via dopant activation using rapidthermal annealing," J. Appl. Phys., vol. 97, no. 6, pp. 066103-1-066103-3, Mar. 2005

[25] K. Ellmer, "Resistivity of polycrystalline zinc oxide films: Current status and physical limit," J. Phys. D, Appl. Phys., vol. 34, no. 21, pp. 30973108, Nov. 2001.

[26] U. Ozgur, D. Hofstetter, and H. Morkoc, "ZnO devices and applications: A review of current status and future prospects," Proc. IEEE, vol. 98, no. 7, pp. 1255-1268, Jul. 2010.
[27] Y. S. Choi, J. W. Kang, D. K. Hwang, and S. J. Park, "Recent advances in ZnO-based light-emitting diodes," IEEE Trans. Electron Devices, vol. 57, no. 1, pp. 26-41, Jan. 2010.

[28] C. Avis, S. H. Kim, J. H. Hur, J. Jang, and W. I. Milne, "Coplanar $\mathrm{ZnO}$ thin-film transistor using boron ion doped source/drain contacts," Electrochem. Solid-State Lett., vol. 12, no. 10, pp. J93-J95, Jul. 2009.

[29] N. Morosawa, Y. Ohshima, M. Morooka, T. Arai, and T. Sasaoka, "A novel self-aligned top-gate oxide TFT for AM-OLED displays," in Proc. SID Tech. Dig., 2011, pp. 479-482.

[30] S. Kohiki, M. Nishitani, and T. Wada, "Enhanced electrical-conductivity of zinc-oxide thin-films by ion-implantation of gallium, aluminum, and boron atoms," J. Appl. Phys., vol. 75, no. 4, pp. 2069-2072, Feb. 1994.

[31] W. W. Wenas, A. Yamada, K. Takahashi, M. Yoshino, and M. Konagai, "Electrical and optical-properties of boron-doped $\mathrm{ZnO}$ thin-films for solar-cells grown by metal organic chemical vapor-deposition," J. Appl. Phys., vol. 70, no. 11, pp. 7119-7123, Dec. 1991.

[32] X. D. Liu, E. Y. Jiang, and Z. Q. Li, "Low temperature electrical transport properties of B-doped ZnO films," J. Appl. Phys., vol. 102, no. 7, pp. 073708-1-073708-4, Oct. 2007.

[33] B. Sang, A. Yamada, and M. Konagai, "Growth of boron-doped $\mathrm{ZnO}$ thin films by atomic layer deposition," Sol. Energy Mater. Sol. Cells, vol. 49, no. 1-4, pp. 19-26, Dec. 1997.

[34] Y. Yamamoto, K. Saito, K. Takahashi, and M. Konagai, "Preparation of boron-doped $\mathrm{ZnO}$ thin films by photo-atomic layer deposition," Sol. Energy Mater. Sol. Cells, vol. 65, no. 1-4, pp. 125-132, Jan. 2001.

[35] J. Sun, D. A. Mourey, D. Garg, and T. N. Jackson, "Boron-doped plasma enhanced chemical vapor deposition of $\mathrm{ZnO}$ thin films," Electrochem. Solid-State Lett., vol. 11, no. 5, pp. D47-D49, Jan. 2008

[36] L. Gao, Y. Zhang, J.-M. Zhang, and K.-W. Xu, "Boron doped ZnO thin films fabricated by RF-magnetron sputtering," Appl. Surf. Sci., vol. 257, no. 7, pp. 2498-2502, Jan. 2011.

[37] J. Y. W. Seto, "Electrical properties of polycrystalline silicon films," J. Appl. Phys., vol. 46, no. 12, pp. 5247-5254, Dec. 1975.

[38] A. Janotti and C. G. Van de Walle, "Fundamentals of zinc oxide as a semiconductor," Rep. Prog. Phys., vol. 72, no. 12, pp. 126501-1-126501-29, Dec. 2009.

[39] R. Wahab, S. G. Ansari, Y. S. Kim, H. K. Seo, G. S. Kim, G. Khang, and H. S. Shin, "Low temperature solution synthesis and characterization of $\mathrm{ZnO}$ nano-flowers," Mater. Res. Bull., vol. 42, no. 9, pp. 1640-1648, Sep. 2007.

[40] M. Chen, X. Wang, Y. H. Yu, Z. L. Pei, X. D. Bai, C. Sun, R. F. Huang, and L. S. Wen, "X-ray photoelectron spectroscopy and auger electron spectroscopy studies of Al-doped ZnO films," Appl. Surf. Sci., vol. 158, no. 1/2, pp. 134-140, May 2000.

[41] A. Janotti and C. G. Van de Walle, "Oxygen vacancies in ZnO," Appl. Phys. Lett., vol. 87, no. 12, pp. 122102-1-122102-3, Sep. 2005.

[42] X. Q. Wei, B. Y. Man, M. Liu, C. S. Xue, H. Z. Zhuang, and C. Yang, "Blue luminescent centers and microstructural evaluation by XPS and Raman in $\mathrm{ZnO}$ thin films annealed in vacuum, $\mathrm{N}_{2}$ and $\mathrm{O}_{2}$," Phys. B: Condens. Matter, vol. 388, no. 1/2, pp. 145-152, Jan. 2007.

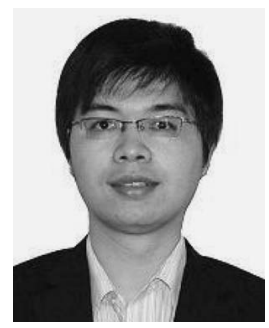

Zhi Ye was born in Hunan, China, in 1982. He received the B.S. degree in measurement and control technology and instrument and the M.S. degree in mircroelectronic technology from Xiangtan University, Hunan, China, in 2004 and 2007, respectively. $\mathrm{He}$ is currently working toward the Ph.D. degree in the Department of Electronic and Computer Engineering, The Hong Kong University of Science and Technology, Kowloon, Hong Kong.

His research interests include $\mathrm{ZnO}$-based thinferroelectric thin-film memory. film transistor structure, methods of fabrication, and 


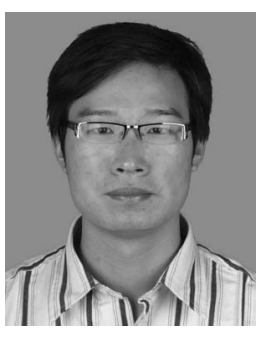

Lei Lu was born in Jiangsu, China, in 1984. He received the B.S. and M.S. degrees in Microelectronics from Soochow University, Jiangsu, China, in 2007 and 2010, respectively. He is currently working toward the Ph.D. degree in the Department of Electronic and Computer Engineering, The Hong Kong University of Science and Technology, Kowloon, Hong Kong.

His research interests include fabrication and reliability of ZnO-based TFTs, CNTs growth and CNTsbased devices.

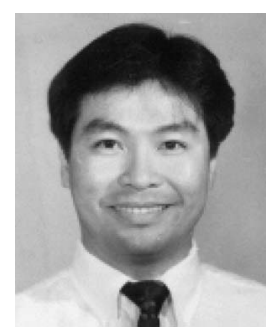

Man Wong (S'83-M'84-SM'00) was born in Beijing, China. He received the B.S. and M.S. degrees in electrical engineering from the Massachusetts Institute of Technology, Cambridge, in 1982 and 1984, respectively, and the $\mathrm{Ph} . \mathrm{D}$. degree in electrical engineering from the Center for Integrated Systems, Stanford University, Stanford, CA

From 1985 to 1988 , he was with the Center for Integrated Systems, Stanford University, where he worked on tungsten-gate MOS technology. From 1988 to 1992 , he was with the Semiconductor Process and Design Center, Texas Instruments, Dallas, where he worked on the modeling and development of integrated-circuit metallization systems and dry/vapor surface-conditioning process. In 2003, he was appointed as an Honorary Guest Professor with Nankai University, Tianjin, China. He is currently with the Department of Electronic and Computer Engineering, The Hong Kong University of Science and Technology, Kowloon, Hong Kong. His research interests include microfabrication technology, device structure and material, physics and technology of thin-film transistor, organic light-emitting diode display technology, modeling and implementation of integrated microsystems, and thin-film solar cell device and process technology.

Dr. Wong is a member of Tau Beta Pi, Eta Kappa Nu, and Sigma Xi. 